\title{
Understanding an Indigenous Indian Himalayan Folklore: Jagar as Emotion Discourse
}

\author{
Dr. Shachi Negi \\ Assistant Professor, DIT University, Dehradun, India
}

\begin{abstract}
Modern approach in urban world is more towards outside development and lesser we are concerned to the emotions inside. In the present scenario, jagar, a ritual performed in rural Uttarakhand attempts to awake and release the deep rooted psyche of human beings. The present paper examines how jagar is performed as emotion discourse in indigenous set-up of central Himalayan, India.

Jagar is a popular folklore of central Himalayas in India which is co-existed with mainstream Hinduism for ages. Traditionally in its classical form, it is performed as ritual to awaken supernatural powers of God, local deities and dead sprits (ghosts). The word Jagar is originated from ancient Indian Sanskrit language, 'jaga' which means to awake. The narrator of jagar is called jagariya who through indigenous musical instruments narrates/ sings ballads of God or dead spirits with allusions to Indian epics: Mahabharat/ Ramayana. In rural Uttarakhand, India, Jagar is an organized ritual to seek divine intervention to the problems or to receive blessings of God. In recent years, jagar has also been diversified as popular music in urban Uttarakhand. The credit of its popularity goes to jagariya as well as folk artist who came forward to exhibit jagar by using various medium of entertainment.

In today's context, Stefan Fiol in his book, Recasting Folk in the Himalayas writes about the significance of jagar as "an important marker of regional belonging and devotional expression for many migrants living far from home"(24). The findings of the study are based on the performance of Jagar in Nerul village in Pauri district, Uttarakhand. The residents of the village and migrants from various states of India have gathered to participate in a five days yajana ceremony from 6 June to 10 June 2019. In the present paper, the jagar and its response among the masses as attendees \& participants has been noted and analyzed as emotional discourse.
\end{abstract}

Keywords: Folklore in Uttarakhand; Hinduism; Supernatural Powers; Emotional Discourse; indigenous; Indian epics 


\section{Introduction}

Jagar, a popular folklore is not mere a leisure activity in Uttarakhand but considered as a significant religious ritual of central Himalayas. The reference of jagar is also mentioned in the Sam Veda, written between 1500 to 1000 BCE, an ancient Vedic Sanskrit text of melodies and chants. Since ancient times, jagar is evident as medium to invite deities by singing their hymns. In $21^{\text {st }}$ century rural Uttarakhand, it is still performed to evoke the deities, spirits and supernatural power, to express emotions, to seek justice and to get healed.

Jagriya is the narrator of jagar who traditionally comes from shilpkar community, historically belongs to a relatively small group of low-status hereditary communities. By singing ballads from laukik $^{1}$ or pauranik ${ }^{2}$, jagariya leads the rituals and two to three people in his team sing and play drums with him. In the villages of central Himalayas in India, Jagriya possess the dignity of Guru (master) or priest and Hurkiyas, the drummers who play hourglass shaped pressure drum, the hurka are the healers of the possession rituals in jagar. Bajgis, the traditional drummers play Dhol damau, the other most significant instruments, played during rituals in Uttarakhand. In his thesis Performance and Identity in Jaunsari Puja Drumming, research scholar Hans Frederick Utter from the Ohio State University in 2006 writes about the strategic pattern of drumming during the ceremony, "The connection of mantras and the bols ${ }^{3}$ of the $d h o l$ are closely linked, and explain the ability of certain talas $^{4}$ to induce trance, grant siddis (special powers), and heal ailments" (61). According to popular belief, the purpose of the drumming and narrations by Bajgi during the puja ceremony is to awaken the deities and to enhance the emotional and spiritual well-being of attendees as well as participants in the ceremony.

The repositories of folk culture portray the collective consciousness where all the individuals of the communities are connected through a heritage, a mythic past and set of similar beliefs. The sound of chanting and drums together create mixed emotions, forming different referents in the minds of different participants. Thus a single ceremony of jagar embodies the interrelationship of emotions, beliefs, culture, verbal and non verbal sounds. According to Singer, in that the participants are expressing a multitude of social, cognitive, and expressive dimensions of their culture both to themselves and to the outside world, both that of Garhwal and the larger context of India as a whole. 


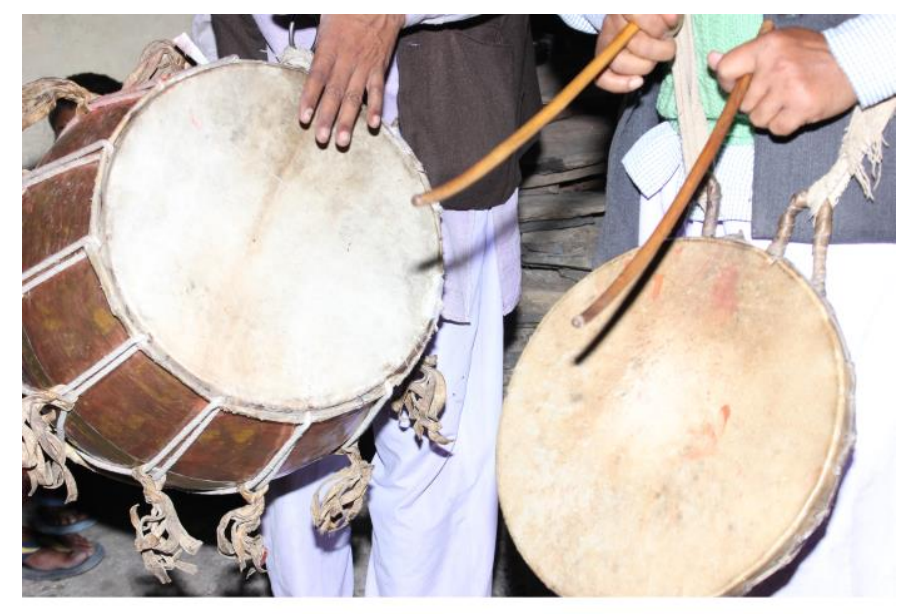

The traditional Drums of Uttarakhand: Dhol (bigger one) \& Dhamav (smaller one)

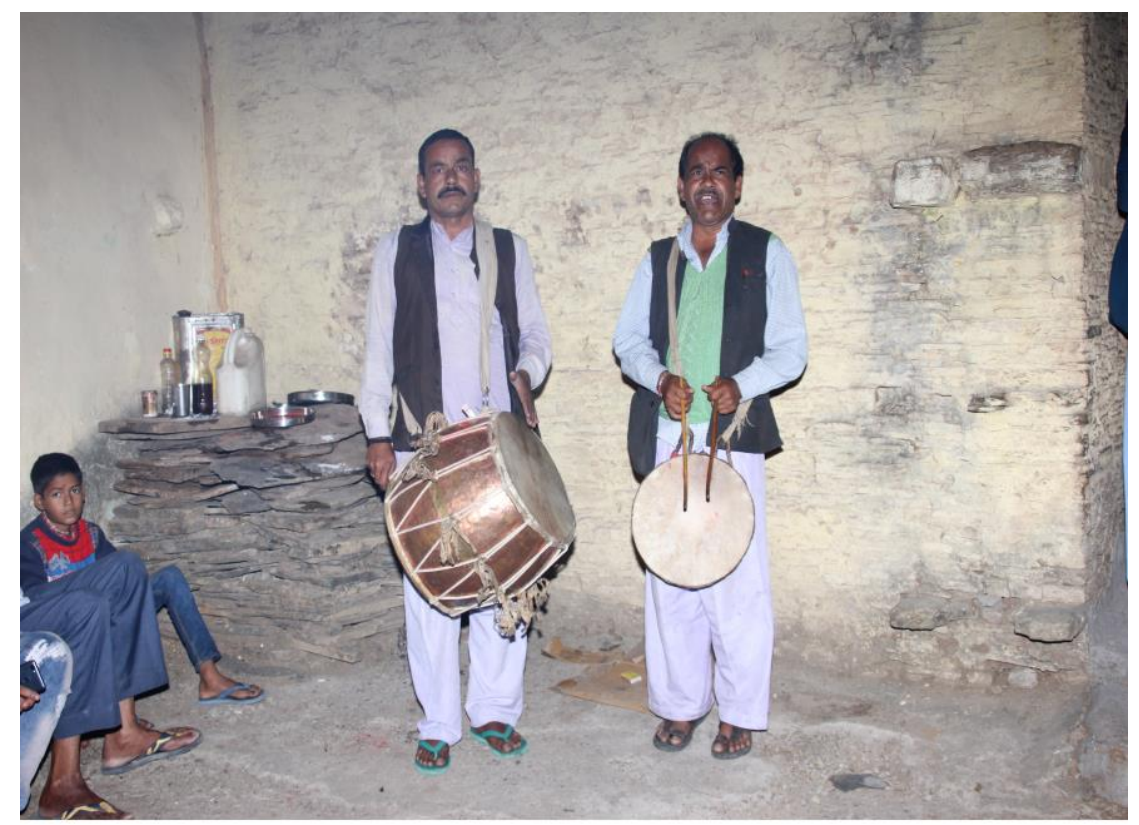

Bajgi performing jagar in the village: Nerul, Uttarakhand, India

Picture taken by Dr. Shachi Negi

Dated : 6.June.2019

\section{Understanding Field Background: Nerul Village, Uttarakhand}

The study is based on the field work of Nerul village, located in Central Himalayas of Pauri District, Uttarakhand. The village is around $100 \mathrm{Km}$ away from Dehradun, the capital of Uttarakhand. To reach the village, one has to cross difficult rocky track for 5 to $7 \mathrm{Km}$. The village is surrounded with dense forest and agriculture is the main occupation of the villagers. 

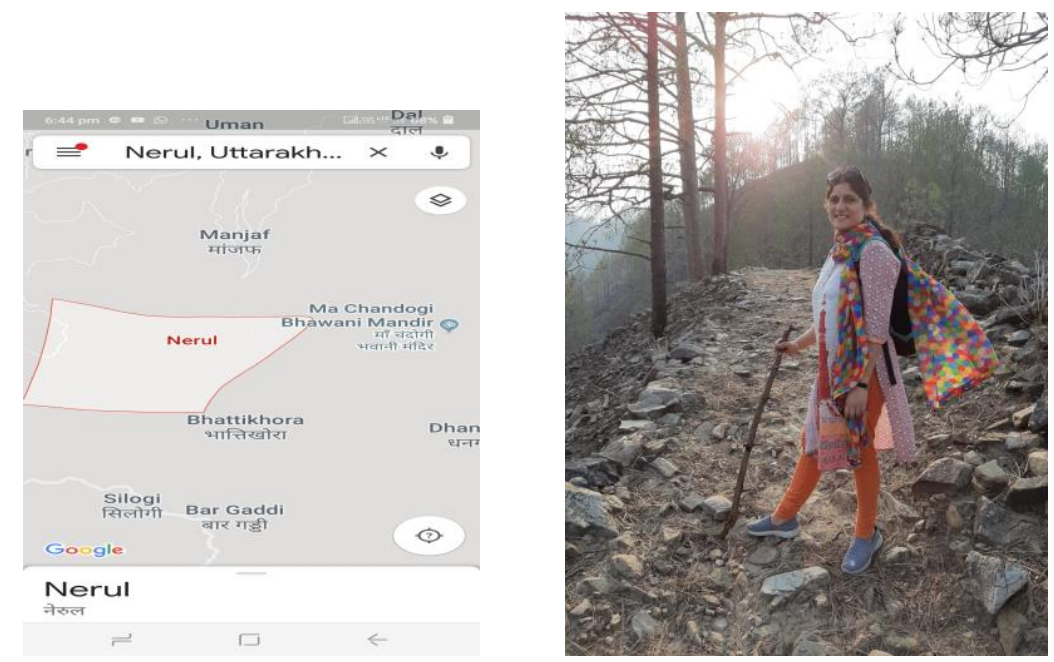

Sixty to seventy percent of the population has already migrated from the village to various cities, but they do visit the village during puja ceremony to pay homage to their deity. This time, the occasion was more special because it was a five days yajana ${ }^{5}$ ceremony (from 6 June to 10 June 2019) which took place after five years in the village to worship the local deity (kul devi), Ma Chandogi Bhavani. The purpose of prayers is to establish the divinity in the atmosphere, purify the spirit through devotion and invoke the presence of the deity. The deity, Ma Chandogi Bhawani is invoked through yajana and the most significantly through jagar. The community believes that the deity always protects them from all the problems and disasters of life. The temple of the deity is situated at the height of the mountain where all the villagers from nearby and far away localities gather to worship. In an interview with a resident of Nerul village Bhagwati Prasad Juyal tells the story behind the temple. He says that according to belief, narrated by the ancestors, the deity has herself chosen the place of temple. She once came in the dream of a villager, Dharmanand Juyal and showed him the place of temple in dream and told him that she will appear in form of linga $a^{6}$ in that place. And the deity in the temple is situated in form of linga.

\section{Jagar as Emotion Discourse}

D. Edward, a psychologist in his research article, Emotion Discourse writes, "Discursive psychology is defined and illustrated in terms of how people describe and invoke emotions in everyday talk and text" (Abstract). Jagar is a way to awaken the deep rooted emotions of the community. Bajgi calls the Godeess through narrations of ballads and beating of drums. The jagar where the deities are invoked are known as dev jagar. The attachment of the villagers with the Goddess is so profound that they wish to express and take blessings from the deity in physical form. Jagar is a way of meeting their Goddess in physical form. In the ritual, the community believes that their deities could be invoked in any of the person present in the ceremony. The person whose body is used as medium to invoke the deity is called the Dagariya $^{6}$. 
On $6^{\text {th }}$ June 2019 at 10:00 P.M in the site of Nerul village, the ritual of jagar has started. After singing and beating of drums by Bajgi for around 15 to 20 minutes, a man of around 40 years appeared dancing and with him an old woman arrives dancing who was believed to be dagariya of Ma Bhawani. The people of village expressed their devotion to the deity. She also blessed them with a smile on her face and also spread tilak ${ }^{8}$ on their forehead as a gesture of blessings. The ritual of jagar opens a way of discourse with an abstract entity and fills the worshipers with the fulfillment of meeting their beloved Deity. He expresses his unexpressed emotions to her and feels relaxed after the discourse. The present discourse makes them hopeful and optimistic in their difficult lives.

According to the past experiences of the villagers, they are always relieved from all types of mental, physical and emotional problems after the jagar ceremony. Richard Schechner and Victor Turner were also important in the development of performance studies. Turner's conception of "social drama" employed an analytic model developed from dramatic structures, and considered performance as a central feature of a wide array of human rituals and ceremonies. A ritual is an 'efficacious' performance, that is, it is a performative act with a specific effect (Turner: 1969; Schechner: 1993). Performance is fundamentally a type of experience, and sets symbolic categories in a living, fluid relationship, mediated between the performance, the audience, and the cultural system (Turner 1982: 15-17). Thus, performance can be the site of the negotiation and transformation of the self and society.
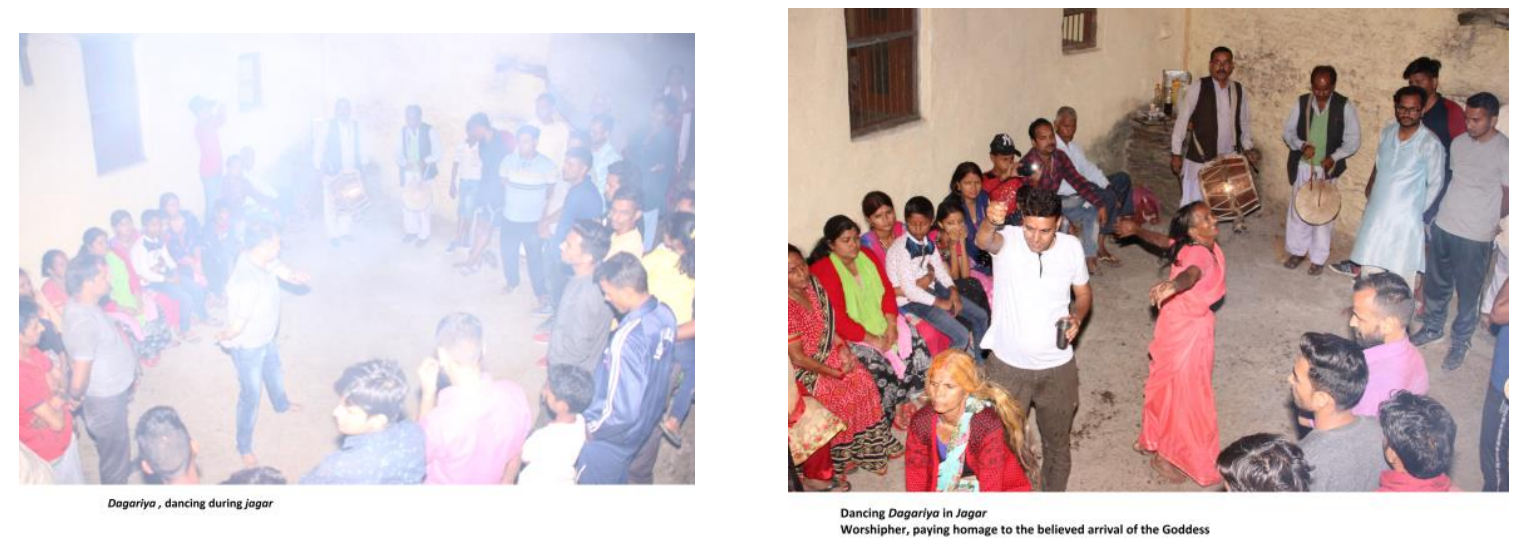

To understand jagar more as an emotion discourse, I met with Basanti Bisht who is a well known folk singer of Uttarakhand and also popular for being the first woman singer of the Jagar. She is also acknowledged with Padam Shri ${ }^{9}$ by Government of India in 2017 for promoting jagar. Born in 1953, in Luani village in Chamoli, Uttarakhand, she has seen jagar in early times. In an interview she shares her experience that the narrations through singing ballads evoke the emotions and emotions have power to invoke the Gods.

Sharing her childhood experience with jagar, she recalls that those were the tough days and in the isolated villages in hills of Uttarakhand, jagar was the only solution to overcome many types of problems of life. Basanti Bisht shares her personal experience that her mother's 
infertility issue was resolved through the process of jagar, not only this, she further says that she has seen many people with mental disorders, get cured by listening jagar.
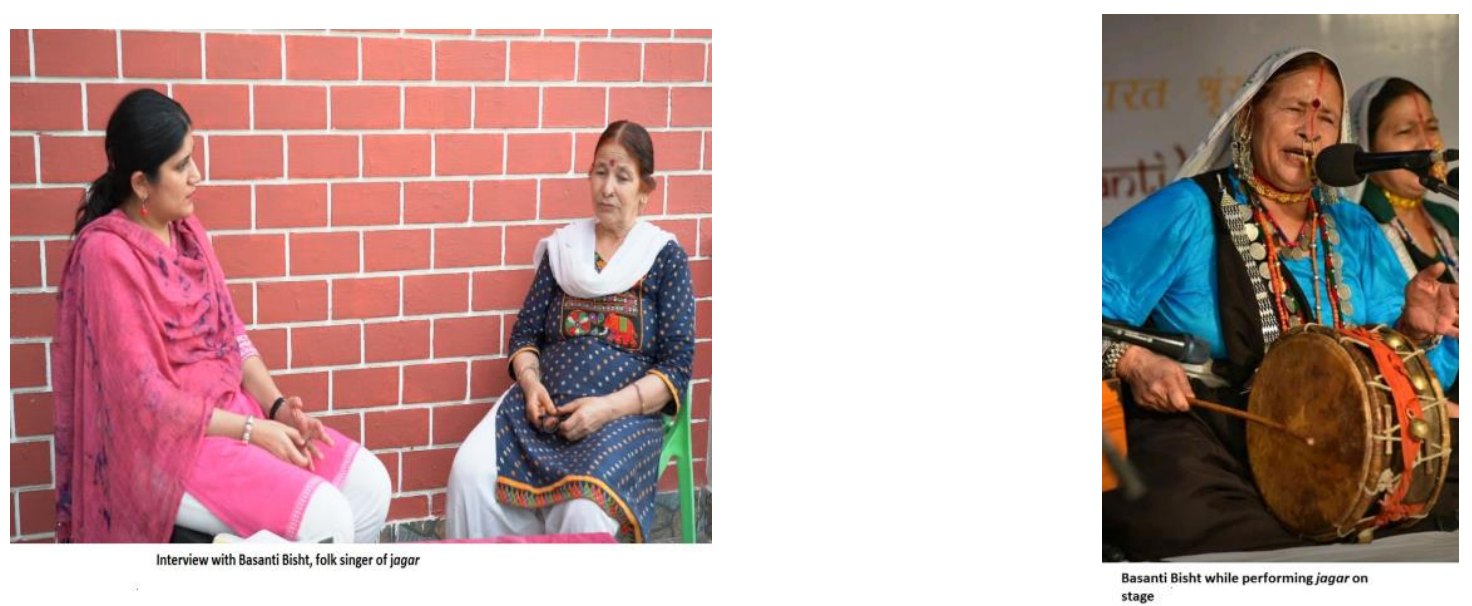

\section{Conclusion}

Herder in his book, Folklore Studies in Multicultural World postulated that the presence of folk music and poetry benefited the nation as a whole; nonetheless, it was not found in equal measure everywhere. It was the task of social elites to find and nurture the production of folk music in the "common man", among whom it was thought to emerge spontaneously and instinctively. It seems that the survival of archaic belief and customs in modern ages is difficult but their simple ways no doubt gives a new way out to overcome difficult issues of modern world. Jagar helps and supports the villagers to exhibit their deep emotions; it gives them a platform to express themselves in emotion discourse. It also gives us scope to find solutions in simple indigenous ways.

\section{References}

Edwards, D. (1999). Emotion discourse. Culture \& Psychology, 5(3), 271-291.

<http://dx.doi.org/10.1177/1354067X9953001>

Fiol, Stephen. Recasting Folk in the Himalayas Indian Music, Media, and Social Mobility. University of Illinois. 2017.

Singer, Milton. When a Great Tradition Modernizes. New York: Praeger. 1972

Turner, Victor. .The Ritual Process. Chicago: Aldine Publishing House, 1969. 
Utter,Hans Frederick. PERFORMANCE AND IDENTITY IN JAUNSARI PUJA DRUMMING. The Ohio State University. 2006

\section{Appendices}

1. Laukik are the stories based on day to day lives in village.

2. Pauranik are the stories or ballads based on classical mythologies.

3. Bols are words, verbal communication.

4. Talas mean rhythm.

5. Yajana Yajana (यजन) refers to the name of a Tīrtha (pilgrim's destination) Yajana is a Sanskrit epic poem in the Hindu Epic, Mahabharata.

6. Linga is a Sanskrit word which means sign, symbol or mark. It is an abstract or aniconic representation of Hindu deity, Shiva. These are self- manifested natural objects which are not man- made.

7. The word Dagariya comes from the Kumaoni word Dagar, which means way.The Dagariya is the one who shows the way for the gods.

8. Tilak is worn by Hindus on their forehead as a symbol of auspiciousness.

9. Padma Shri is the fourth highest civilian award in the Republic of India, after the Bharat Ratna, the Padma Vibhushan and the Padma Bhushan. It is awarded by the Government of India, every year on India's Republic Day. 